\title{
The ever changing face of digital curation: introduction to the special issue on digital curation
}

\author{
Milena Dobreva $\cdot$ Wendy M. Duff
}

Published online: 3 March 2015

(C) Springer Science+Business Media Dordrecht 2015

According to Yakel (2007), "Digital Curation is the active involvement of information professionals in the management, including the preservation, of digital data for future use" (p. 335). The call for papers for this special issue stated, "digital curation involves the selection, maintenance, dissemination, preservation and adding value to digital assets. Examples of these activities include the development of repositories for digital resources, the creation and/or selection of digital assets; creation and management of metadata; file format identification and management, and provision for dissemination and access to digital assets". In creating a special issue, the guest editors posited that digital curation has much relevance to the archival community.

Digital curation is a multidisciplinary field, drawing upon the domain knowledge of many disciplines including archival, information, library, and computer science though communication among these disciplines continues to present challenges. The relationship between archival science and digital curation is a bidirectional continuum: on one hand, digital curation employs archival principles and concepts, such as authenticity and integrity, and requires the preservation of an object's context as well as its content and structure; on the other hand, digital curation has the potential to challenge and expand the boundaries of archival science.

Curation of trusted objects is a complicated activity; not only is the complexity of digital objects increasing, but also the contexts of use in which these objects need to be captured, preserved, and re-created continue to evolve. The types of digital assets

\footnotetext{
M. Dobreva

Head of the Library Information and Archive Sciences Department, Faculty of Media and Knowledge Sciences, University of Malta, Msida, Malta

W. M. Duff $(\bowtie)$

Faculty of Information, University of Toronto, Toronto, Canada

e-mail: wendy.duff@utoronto.ca
} 
requiring curation are growing and changing over time. As Rusbridge et al. (2005) point out, the "long term stewardship of digital assets is the responsibility of everyone in the digital information value chain" (p. 31) not just the information professional. Furthermore, the field has moved far beyond its original focus on the preservation of different file formats and the curation of research data to the preservation of the context of digital objects made more challenging and complex by new types of digital assets software and processes (see Fig. 1).

In the last year, curation research attention has shifted its focus from data or the development of stand-alone trusted repositories to multifaceted environments that include a plethora of complex objects. For example, a recent edited collection by Delve and Anderson (2014) explores the issues around preservation of simulations, digital art, and games. Preservation in this field is still a highly exploratory domain, and commonly accepted approaches and solutions are still developing. Other emerging areas include curation of linked open data-which is not only a complex object but also very dynamic, as well as crowd curation of digital assets, which also requires critical analysis from an archival perspective. These new trends are expanding the traditional boundaries of exploration in archival science.

The response to this special issue's call for papers foregrounds the breath and depth of digital curation research and the methods digital curation researchers are employing. The four papers published in this special issue illustrate the challenges archivists must deal with as they expand their role to embrace digital curation.

In the first article in the collections, "How Has Your Science Data Grown? Digital Curation and the Human Factor: a Critical Literature Review", Alex Poole reviews the research literature on aspects of sharing, accessing, and reuse of research data. This paper provides an overview of the complex fabric of data curation, the stakeholders involved, as well as issues requiring further work. This

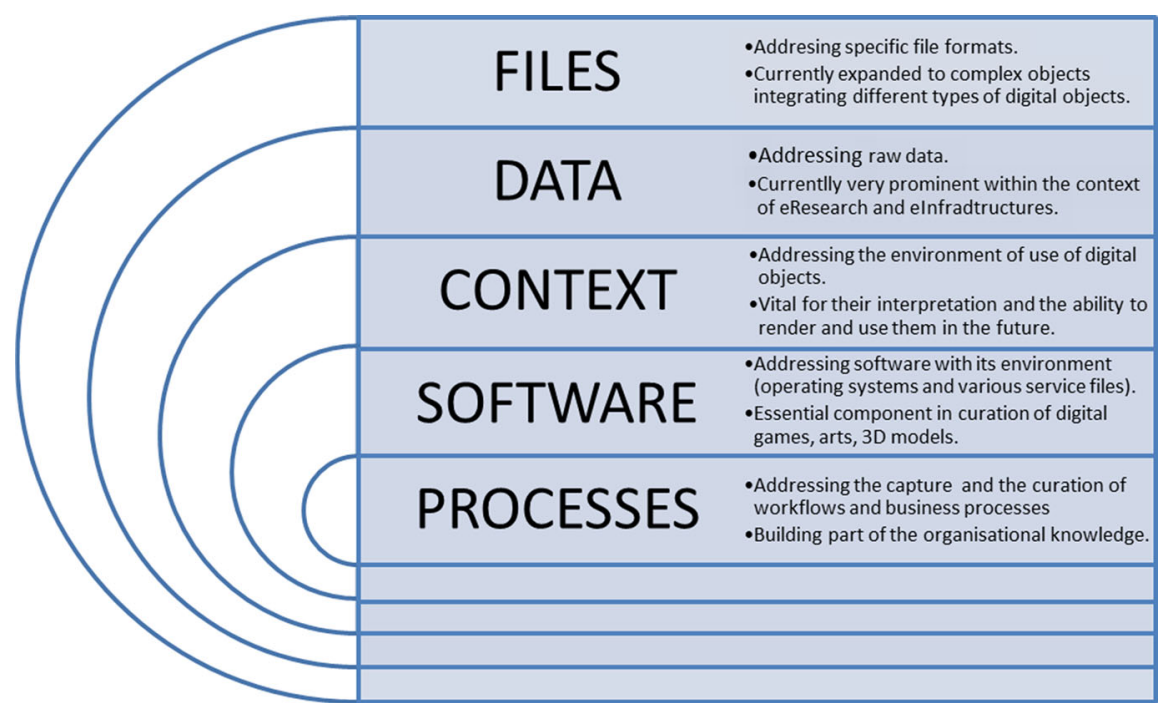

Fig. 1 Evolution of digital curation areas of application 
extensive literature study provides insights into the pressing issues related to data curation. The paper focuses its exploration on the domain within the North American and UK context. It provides an introduction to the various components of the human infrastructure of science data curation including cyberinfrastructure (which translates to e-Infrastructure in the European context), research communities, collaboration, planning, policy, and standards and best practices. The article revisits the archival principles (provenance, selection and appraisal, authenticity, metadata, risk management, and trust) within the data curation context. Investigating areas for further research, Poole suggests a number of areas requiring researchincluding sustainability, costing, planning and policy, education, training and skilling up, researcher practices, and raising awareness.

Rebecca D. Frank, Elizabeth Yakel, and Ixchel M. Faniel explore in further depth data curation in two specialised domains: archaeology and zoology, in the article "Destruction/Reconstruction: Preservation of Archaeological \& Zoological Research Data". This paper reports on the findings from research involving 49 interviews with researchers from two domains (27 zoologists and 22 archaeologists); the research aimed to understand the internal and external factors that influence decisions and actions concerning preservation. The research found internal factors related to data collection and data management/recordkeeping and external factors related to funding, legal requirements, and the status of museums and repositories were the most pressing. The article concludes that within the context of data destruction, researchers are motivated to find ways to preserve their data, but considerable scepticism about data preservation still remains in both domains.

The third article by Guillaume Boutard "Towards Mixed Methods Digital Curation: Facing Specific Adaptation in the Artistic Domain" explores digital curation challenges in the artistic domain. It proposes a model for mixed methods digital curation (MMDC), adding a vertical dimension to the popular digital curation life cycle model to accommodate the needs of the artistic domain. One of the specific challenges in this domain is the preservation of work-specific software; thus the article explores epistemological specific features of the domain and discusses how these features impact software. Unlike the software for mass use, the article highlights the difficulty of preserving software tools designed as part of an artwork. These objects present greater risks and effort due to their uniqueness.

And finally, the article "Digital Curation and Quality Standards for Memory Institutions: PREFORMA Research Project” by Antonella Fresa, Börje Justrell, and Claudio Prandoni illustrates new areas addressed in the most recent European Commission (EC) research plan. The intensified transfer of digital assets within the context of memory institutions and the need to preserve digital cultural heritage content were among the issues EC grants sought to address. PREFORMA (PREservation FORMAts for culture information/e-archives) aimed to identify the critical factors in the quality of standard implementation in the memory institutions context. The article suggests digital curation requires the establishment of an ecosystem including tools that preserve objects while minimising the risk of losing digital content. The article elaborates on the methodological approaches and difficulties and illustrates how such a novel ecosystem could be established. This paper is a case study of work in progress - which, however, has the onerous task of 
finding a scalable solution that is adaptable across the rich and diversified memory institutions landscape.

These articles in their totality illustrate the wide variety of research projects that fall under the rubric of digital curation. They highlight the domains of art, archaeology, and zoology from the ever expanding areas of domains that need curating. We hope that this collection of essays will provide insight and lead to a deeper understanding of the connections between archival science and digital curation.

\section{References}

Delve J, Anderson D (eds) (2014) Preserving complex digital objects. Facet, London

Rusbridge C, Buneman P, Burnhill P, Giaretta D, Ross S, Lyon L, Atkinson M (2005) The digital curation centre: a vision for digital curation. Local to global data interoperability-challenges and technologies, pp 31-41. doi:10.1109/LGDI.2005.1612461

Yakel E (2007) Digital curation. OCLC Syst Serv 23:335-340. doi:10.1108/10650750710831466

Milena Dobreva is an associate professor and currently Head of the Library Information and Archive Sciences Department, Faculty of Media and Knowledge Sciences of the University of Malta. She served as the founding head of the first Digitisation Centre in Bulgaria and contributed to the preservation cluster of the DELOS network of excellence in digital libraries. She is co-directing a series of international summer schools on Access to Digital Archives. Her latest research interests are in the areas of citizen science and impact of digital resources.

Wendy M. Duff is a professor at the University of Toronto, School of Information. She was the founding Director of the Digital Curation Institute and she teaches courses in the archives and records management concentration with a focus on access to archival materials and community archives. She is a founding member of AX-SNet, an evolving international team of researchers interested in facilitating access to primary materials. Her current research focuses on archival users, measuring impacts, digital curation, and social justice. 